\title{
ASO Visual Abstract: Upstaging of Fibroepithelial Lesions-A Single-Institution Experience
}

Srivarshini Cherukupalli Mohan, MD 망, Joshua Tseng, MD, Ashley Marumoto, MD, Stephanie Angarita, MD, Farnaz Dadmanesh, MD, Farin Amersi, MD, Armando Giuliano, MD, and Alice Chung, MD

Division of Surgical Oncology, Department of Surgery, Cedars Sinai Medical Center, Los Angeles, CA

Fibroepithelial lesion of the breast (FEL) can pose a diagnostic challenge with a core needle biopsy (CNB) because cellular fibroadenoma is difficult to distinguish from phyllodes tumor (PT). In this 10-year single-institution experience with FEL (https://doi.org/10.1245/s10434-
021-10931-0), age, size of tumor, mitotic activity, and stromal overgrowth on the CNB were predictive of PT after excision, and FEL on CNB was upstaged to PT in $25.8 \%$ of the resected cases. To rule out phyllodes tumor, FEL on CNB warrants excision.

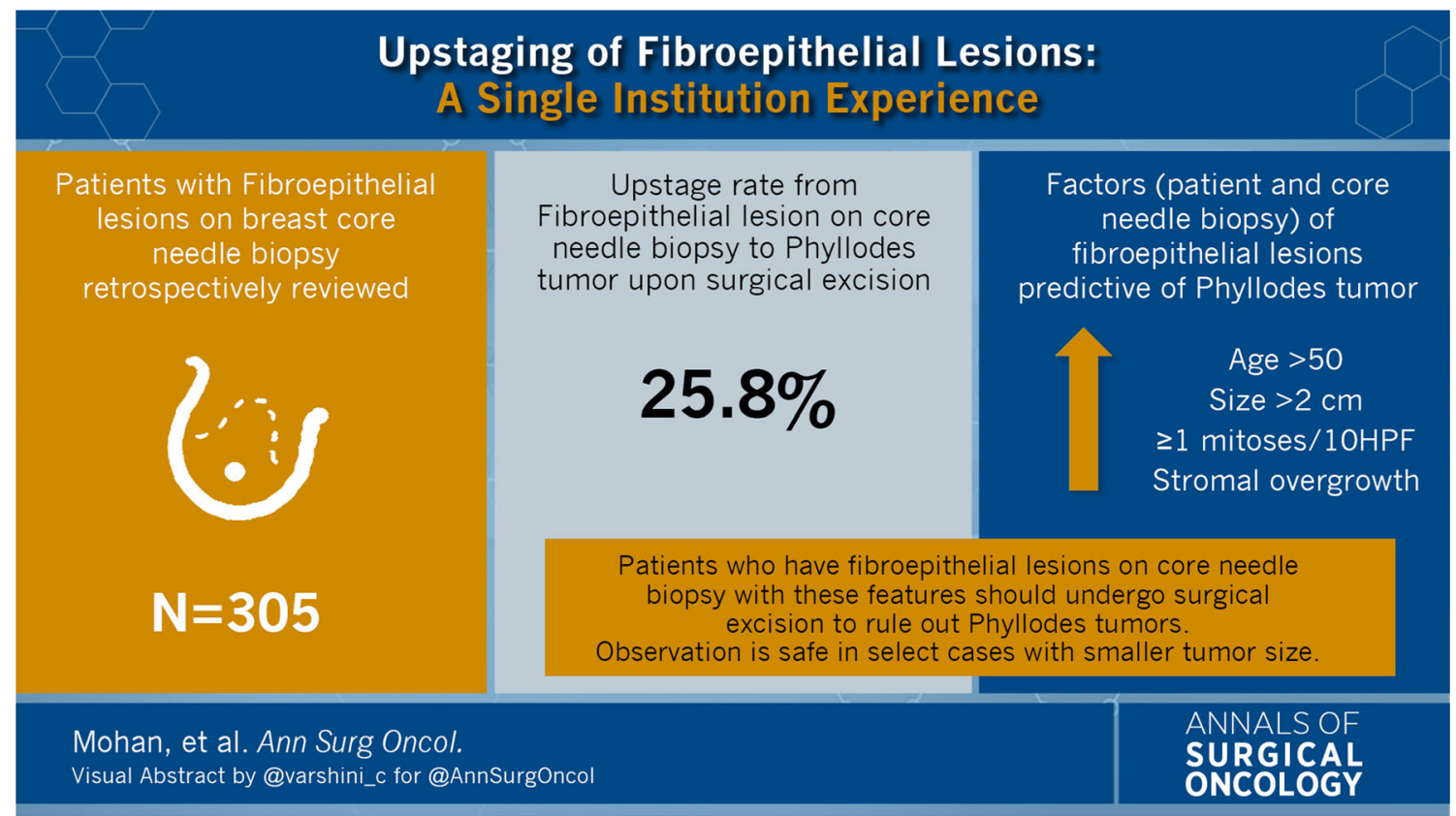

This research was selected for a poster presentation at the 2021 Society of Surgical Oncology virtual meeting, March 18-19, 2021.

(C) Society of Surgical Oncology 2022

A. Chung, MD

e-mail: alice.chung@cshs.org
FUNDING No funding was received for this study.

DISCLOSURE There are no conflict of interest.

Publisher's Note Springer Nature remains neutral with regard to jurisdictional claims in published maps and institutional affiliations. 